\title{
Statistical analysis of second repair welding on dissimilar material using Taguchi method
}

\author{
N. I. S. Hussein, S. Laily*, M. S. Salleh and M. N. Ayof \\ Faculty of Manufacturing Engineering, Universiti Teknikal Malaysia Melaka \\ Hang Tuah Jaya, 76100, Durian Tunggal, Melaka, Malaysia. \\ *Phone: +60166360247 \\ *Email: surayalaily@gmail.com
}

\begin{abstract}
This paper presents an experimental investigation on effect of welding parameter to repair welding of dissimilar material using Gas Metal Arc Welding (GMAW) machine. Taguchi Method has been used to analyse the statistical analysis by using Minitab Software. Repair welding getting more popular nowadays due to saving cost and prolong the material service life. The effect of repair welding of dissimilar material on mechanical properties have been studied. Statistical analysis using Taguchi Method by Minitab Software with three times repetition of L9 orthogonal array. Setting up GMAW machine with current (150A-170A), voltage (17V-21V) and jig rotational speed (50rpm-100rpm) were prepared with $3.00 \mathrm{~mm}$ of Stainless Steel 304L and 3.60mm Carbon Steel 1387.Result shows that voltage gave a huge impact to tensile testing and micro hardness of second repair welding. While current and jig rotational speed gave less impact to responses. The benefit shown has caused repair welding to be accepted and applied in the industry. Regular and total maintenance is able to contribute to the savings while producing good preventive maintenance schedule.
\end{abstract}

Keywords: Gas Metal Arc Welding (GMAW); repair welding; Taguchi method.

\section{INTRODUCTION}

Welding of dissimilar metal is one of joining process, widely used in nuclear material industry for coolant piping, valve bodies and vessel internals. This is due to their excellent mechanical properties such as long lasting period of usage and high strength $[1,2,3]$. The material properties with good corrosion resistance and less expenditure are part of the major reason for using dissimilar material metal welds $[4,5,19]$. One of the most current discussion in repair welding is the popularity of process due to structure integrity and elongated service life of the material [6,7]. Some of the previous researcher have studied that the maximum weld repair at the same part is maximum to two times [7].

Repair welding process is needed when there is defect located in weld area. The weld area had to be eliminated or removed by grinding process to ensure the effective removal can be re - weld according to welding procedure. Repair welding is one of the processes of important maintenance and repair. In joining industry, repair welding is one of processes which more advanced than manufacturing [2]. 


\section{METHODS AND MATERIALS}

\section{Dissimilar pipe preparation}

Figure 1 shows dissimilar material pipe which are Stainless Steel 304L (AISI 304L) and Carbon Steel 1387 (BS 1387) as the main material. Both of them are cut into 100mm long and $3.00 \mathrm{~mm}$ width of AISI $304 \mathrm{~L}$ and $3.60 \mathrm{~cm}$ width of BS 1387. Surface inside and outside of the pipe have been grinded in order to remove any burr.

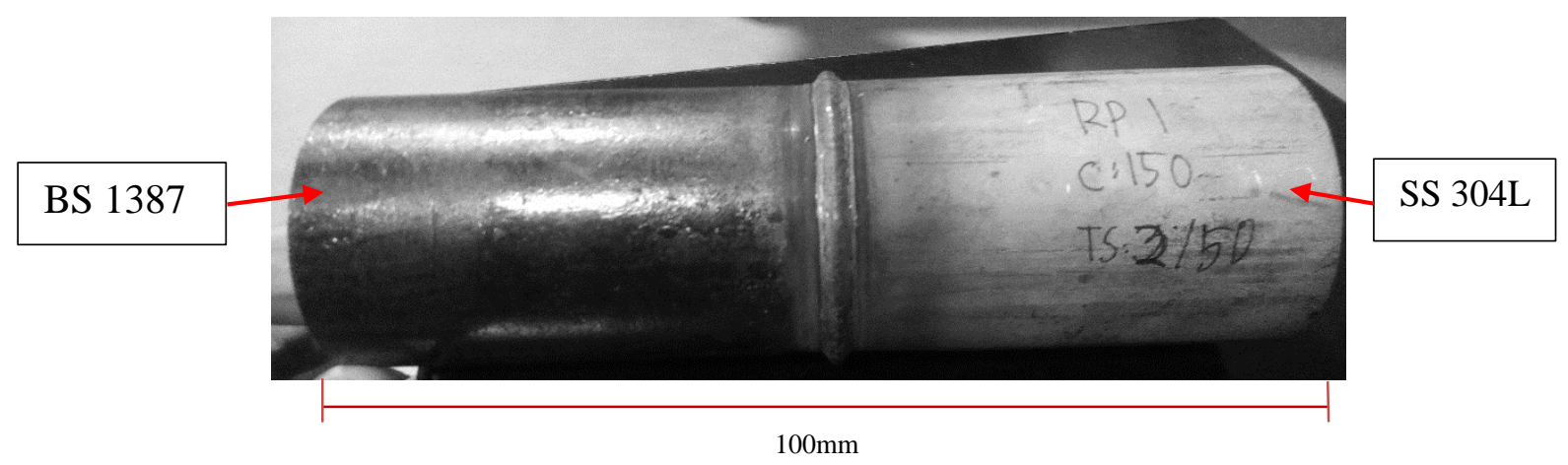

Figure 1. Dissimilar pipe of AISI 304L and BS 1387.

Tacking process is one of the important parts in order to join both of the pipes by using Tungsten Inert Gas Welding. Tack welding is a vital part of a pressure vessel fabricated by welding. This is why the ASME Boiler and Pressure Vessel Code require qualification of the welding procedure used for tack welding $[8,9]$. The tacking code requires the tack welding procedure, the same as for other weldments. Figure 2 shows four tacking point around the pipe with distance $1.0 \mathrm{~mm}$ width of stainless steel wire.

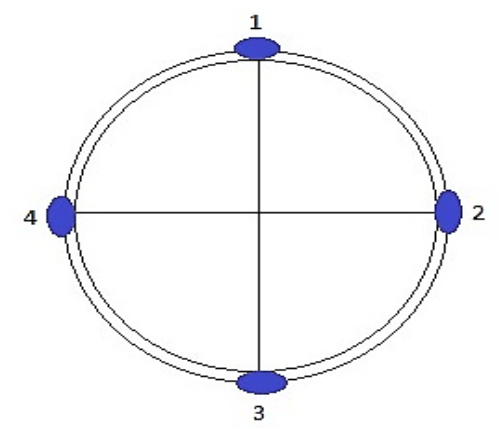

Figure 2: Tacking point.

\section{Design of Experiment (DOE) Using Taguchi Method}

Analysis of the result by using Taguchi Method with current, voltage and rotational speed as set of welding parameter. Run DOE by using Minitab software with L9 run, 3 level of parameters and 3 factors. Table 1 shows welding parameter by using Gas Metal Arc Welding (GMAW). While Table 2 shows the planning matrix suggested by Minitab Software that have been used along the experiment. 
Table 1. GMAW parameter.

\begin{tabular}{|c|c|c|c|}
\hline Parameter & Current (A) & Voltage(V) & Jig rotational spee \\
\hline Range & $120-170$ & $50-100$ & $17-21$ \\
\hline & Table 2. & Planning matrix & \\
\hline Run & $\begin{array}{l}\text { Weld Current } \\
\text { (A) }\end{array}$ & $\begin{array}{l}\text { Jig rotational } \\
\text { speed (rpm) }\end{array}$ & $\begin{array}{l}\text { Voltage } \\
(\mathrm{V})\end{array}$ \\
\hline 1 & 120 & 50 & 17 \\
\hline 2 & 120 & 75 & 19 \\
\hline 3 & 120 & 100 & 21 \\
\hline 4 & 145 & 75 & 17 \\
\hline 5 & 145 & 100 & 19 \\
\hline 6 & 145 & 50 & 21 \\
\hline 7 & 170 & 100 & 17 \\
\hline 8 & 170 & 50 & 19 \\
\hline 9 & 170 & 75 & 21 \\
\hline
\end{tabular}

\section{Repetitive Repair Welding Process}

Experiment's sample that ready to be weld need to grind using grinding paper first before do the welding, in order to remove undesirable contaminant on the pipe's surface. Welding process by using GMAW is shown in Figure 3. Pipe need to be grinded using lathe machine in order to get flat surface before do the repair welding on the same area as shown in Figure 4. This study repeats until second time of repair and the correlation between repair and welding parameter have been studied. Repetitive repair welding process had been explained in Table 3 where it takes two times of grinding and welding before proceed to testing measurement.

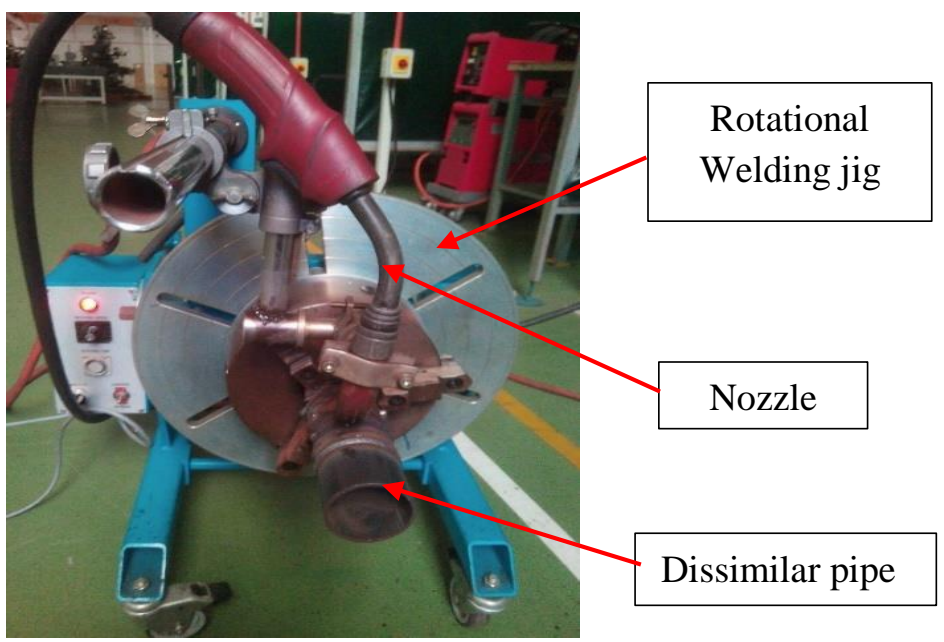

Figure 3. Welding process using jig and GMAW 


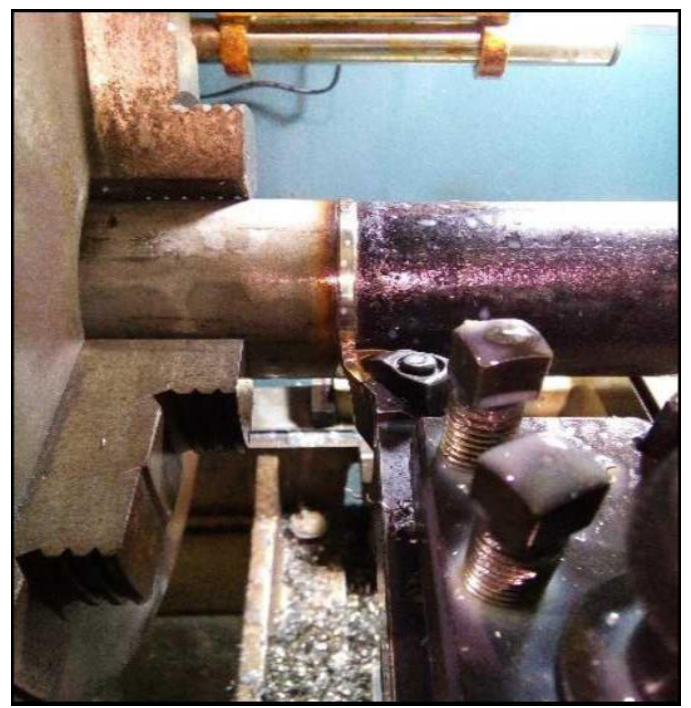

Figure 4. Grinding process using lathe machine.

Table 3: Repair welding description

\begin{tabular}{l} 
Process welding \\
$\begin{array}{l}\text { The original welding had been done by } \\
\text { using original parameter }\end{array}$ \\
$\begin{array}{l}\text { The weldment had been grinded by using } \\
\text { lathe machine. The new weldment were } \\
\text { produced through repair welding }\end{array}$ \\
$\begin{array}{l}\text { The new weldment had been performed } \\
\text { on repair welding process }\end{array}$ \\
\hline
\end{tabular}

Preparation for testing sample

Dissimilar metal pipe has been cut into dog bone shape to prepare for tensile testing using Wire Electrical Discharge Machine (WEDM). All samples then were tested on Universal Tensile Machine (UTM) with 10kN of load. Elongation, Yield Strength and Ultimate Tensile Strength then calculated and plotted into graph. According to ASTM E-8 standard, Figure 5 shows the shape of dog bone for tensile testing. While Figure 6 shows dog bone shape dimension, where cut by using Wire Electrical Discharge Machine (WEDM).

Preparing microhardness testing is according to ASTM E384-08a, applicable force for microhardness testing is within 1 to $1000 \mathrm{gf}$. Therefore, this test method is widely used to test the materials or workpiece which is too small or too thin. The test specimen is desirable to be flat and perpendicular to the axis of indenter. 
As a result, mounting, grinding, polishing and etching is frequently carry out to prepare a flat surface of test specimen. Figure 7 shows dimension of microhardness sample, while Figure 8 stated where is the point taken while indention on sample.

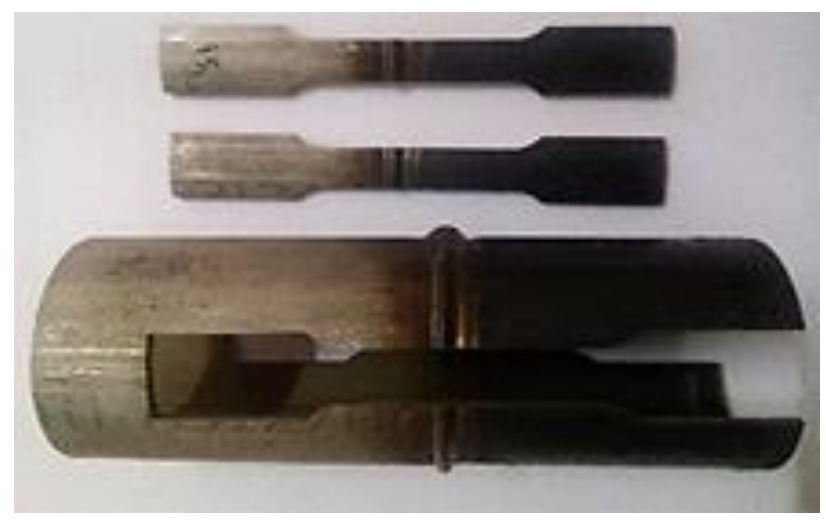

Figure 5. Tensile testing specimen.

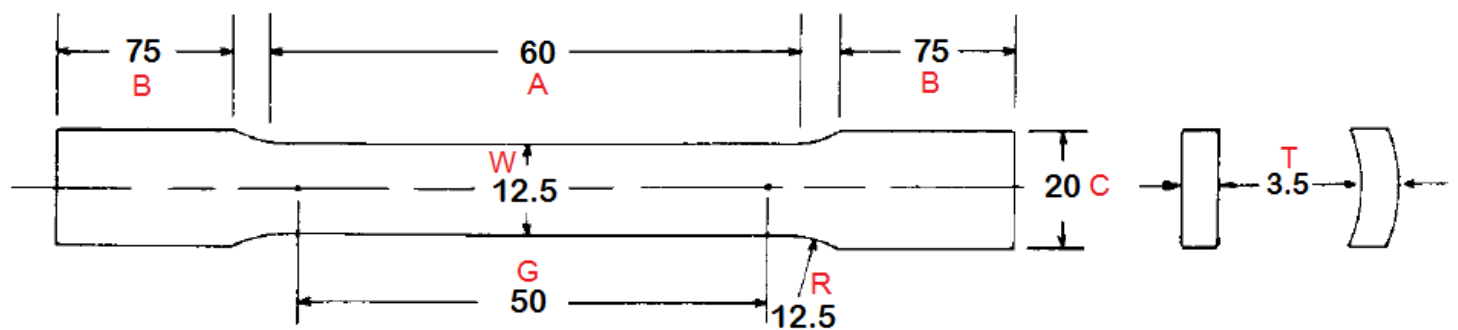

Figure 6. Dimension of tensile testing specimen (ASTM E384-08a).

where, $\mathrm{A}$ is the distance between shoulders, $\mathrm{B}$ is the grip section, $\mathrm{C}$ is the width of grip section, $\mathrm{G}$ is the reduced section, $\mathrm{T}$ is the height section and $\mathrm{W}$ is the diameter of width.

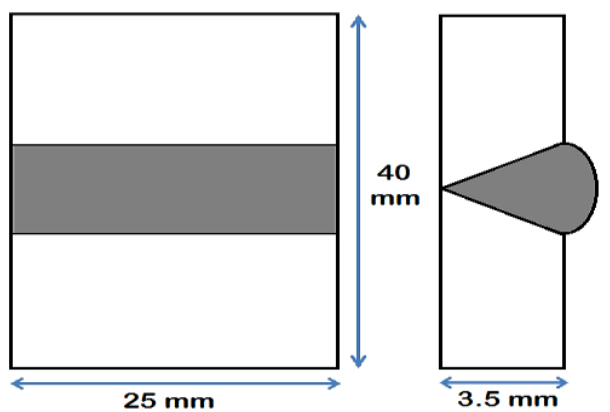

(a)

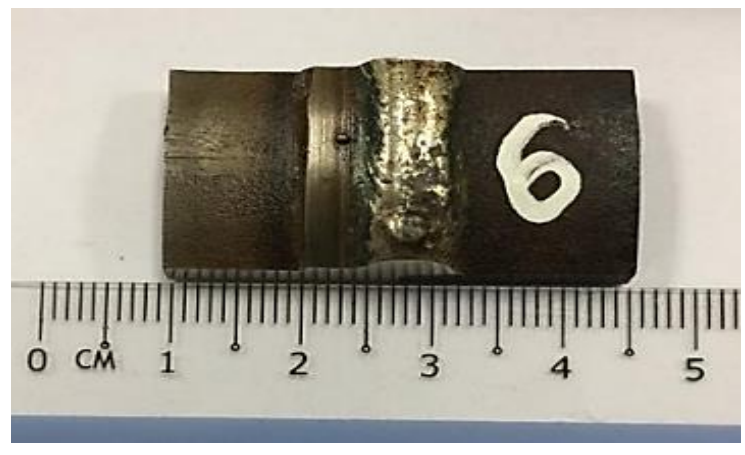

(b)

Figure 7. Microhardness sample: (a) dimension of microhardness sample and (b) sample of microhardness testing 


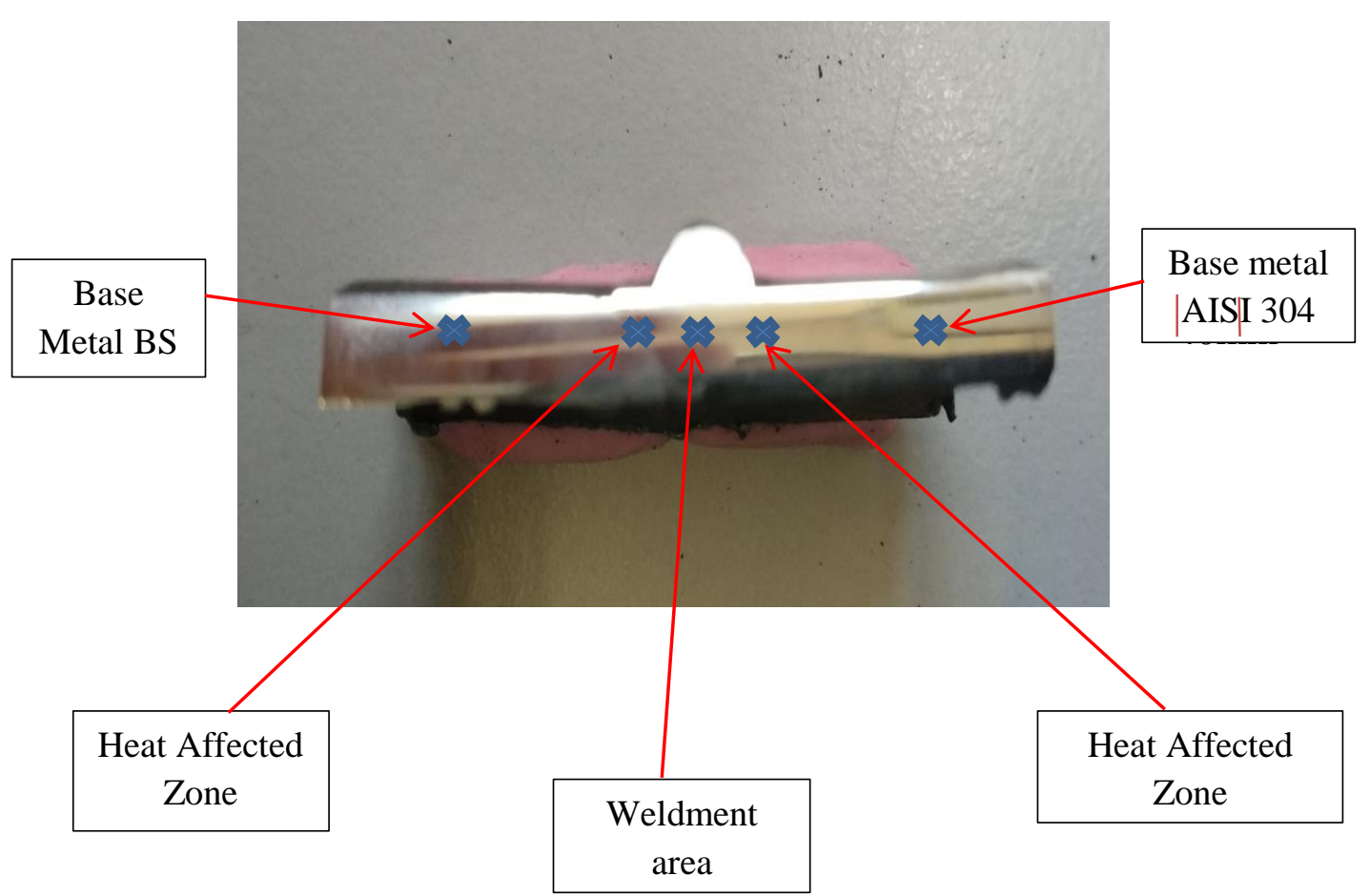

Figure 8. Microhardness indention area.

\section{RESULTS AND DISCUSSION}

\section{Result on tensile testing}

The measurement of yield strength, elongation and ultimate tensile strength are using Universal Tensile Machine (UTM). Previous studies have been used the same standard and procedure $[10,11]$. Table 4 shows result on tensile testing with three times of repetition. By plotting the graph on Minitab Software, Figure 9 is a main effect graph shows that current gave a huge impact to tensile testing with setting up larger is better for $\mathrm{S} / \mathrm{N}$ ratio graph [18]. The graph is generated from Minitab Software after filled in all the results. Furthermore, the current graph is more diverging than voltage and rotational speed, where it can be assumed that current is the most significant factor effected tensile testing. While voltage gave the second-high impact and rotational speed give less impact to tensile result. Table 5 clearly shows and proof that current gave the highest impact to tensile testing due to the ranking of signal to noise ratio. This is agreed with other researcher where mentioned about weld current and voltage mostly effected on welding responses $[12,13,16]$. Optimum value parameter can be obtained from the graph, where the highest peak of each graph parameter shows the optimum value. The optimum value is when current $170 \mathrm{~A}$, voltage $21 \mathrm{~V}$ and jig rotational speed 50rpm. Equation 1 is used to determine the optimum value of Ultimate Tensile Strength (UTS) by using regression equation. 
Table 4. Result on tensile testing.

\begin{tabular}{llllll}
\hline Run & $\begin{array}{l}\text { Weld } \\
\text { Current }(\mathbf{A})\end{array}$ & $\begin{array}{l}\text { Jig } \\
\text { rotational } \\
\text { speed (rpm) }\end{array}$ & $\begin{array}{l}\text { Voltage } \\
(\mathbf{V})\end{array}$ & $\begin{array}{l}\text { UTS } \\
(\mathbf{M P a})\end{array}$ & $\begin{array}{l}\text { Elongation } \\
(\boldsymbol{\%})\end{array}$ \\
\hline $\mathbf{1}$ & 120 & 50 & 17 & 276.302 & 10.14 \\
$\mathbf{2}$ & 120 & 75 & 19 & 254.672 & 8.69 \\
$\mathbf{3}$ & 120 & 100 & 21 & 334.898 & 12.31 \\
$\mathbf{4}$ & 145 & 75 & 17 & 277.079 & 10.14 \\
$\mathbf{5}$ & 145 & 100 & 19 & 287.823 & 9.42 \\
$\mathbf{6}$ & 145 & 50 & 21 & 372.219 & 11.59 \\
$\mathbf{7}$ & 170 & 100 & 17 & 359.849 & 10.87 \\
$\mathbf{8}$ & 170 & 50 & 19 & 421.132 & 10.87 \\
$\mathbf{9}$ & 170 & 75 & 21 & 439.156 & 13.04 \\
\hline
\end{tabular}

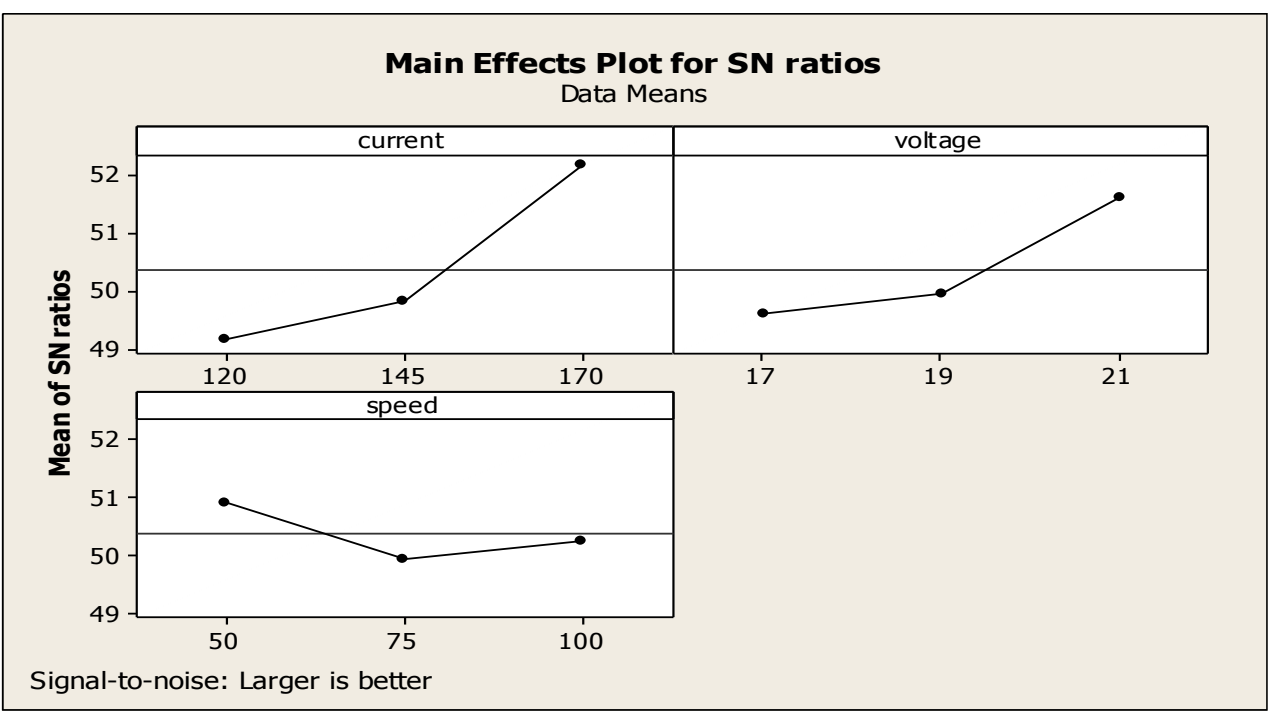

Figure 9. Graph of SN ratio against parameters (main effect plot for $\mathrm{SN}$ ratio for tensile testing).

Table 5. Response table for Signal to Noise Ratio for tensile testing

\begin{tabular}{cccc}
\hline Level & Current & Voltage & Speed \\
\hline $\mathbf{1}$ & 49.15 & 49.60 & 50.91 \\
$\mathbf{2}$ & 49.82 & 49.93 & 49.94 \\
$\mathbf{3}$ & 52.15 & 51.59 & 50.27 \\
Delta & 3.01 & 1.99 & 0.97 \\
\hline Rank & 1 & 2 & 3 \\
\hline
\end{tabular}


Using the regression and correlation analysis, mathematical model for UTS is as follows:

$$
\text { UTS : }-388+1.21 \mathrm{I}+26.6 \mathrm{~V}+0.569 \mathrm{v}
$$

\section{Result on microhardness testing}

Table 6 shows three times of repetition on every sample with five point of hardness points. Plotting graph using Taguchi method shows that current also gave a huge impact to microhardness value, while rotational speed give second highest impact and voltage gave less impact. It can be described on Table 7 where the ranking of response table shows that current in first ranking, followed by jig rotational speed and voltage. Furthermore, some researcher has agreed where hardness of weldment increased due to carburization which make the weldment prone to brittleness $[14,15,17]$. Other than that, from the main effect graph, the highest peak of each graph shows the optimum value. To get optimum value of microhardness, the optimum value is current $170 \mathrm{~A}$, voltage $21 \mathrm{~V}$ and jig rotational speed $75 \mathrm{rpm}$. Equation 2 is to determine optimum value of parameter by using regression equation.

Table 6. Result on microhardness testing.

\begin{tabular}{llllllllll}
\hline Specimen & $\mathbf{1}$ & $\mathbf{2}$ & $\mathbf{3}$ & $\mathbf{4}$ & $\mathbf{5}$ & $\mathbf{6}$ & $\mathbf{7}$ & $\mathbf{8}$ & $\mathbf{9}$ \\
\hline Trial 1 & 153.21 & 173.42 & 190.0 & 173.8 & 165.5 & 171.3 & 180.9 & 165.32 & 174.42 \\
& & & 5 & 2 & 0 & 4 & 8 & & \\
Trial 2 & 155.34 & 174.71 & 188.7 & 179.9 & 165.8 & 172.7 & 179.0 & 159.87 & 172.71 \\
& & & 3 & 0 & 9 & 7 & 3 & & \\
Trial 3 & 157.21 & 177.80 & 186.7 & 174.3 & 167.7 & 170.9 & 179.6 & 159.56 & 173.21 \\
& & & 6 & 2 & 1 & 1 & 6 & & \\
Average & 155.25 & 175.31 & 188.5 & 176.0 & 166.3 & 171.6 & 179.8 & 161.58 & 173.44 \\
$\begin{array}{l}\text { (VHN) } \\
\text { Heat Input } \\
\text { (kJ/min) }\end{array}$ & 3.89 & 2.59 & 1.94 & 3.00 & 2.25 & 4.49 & 2.49 & 4.98 & 3.32 \\
\hline
\end{tabular}

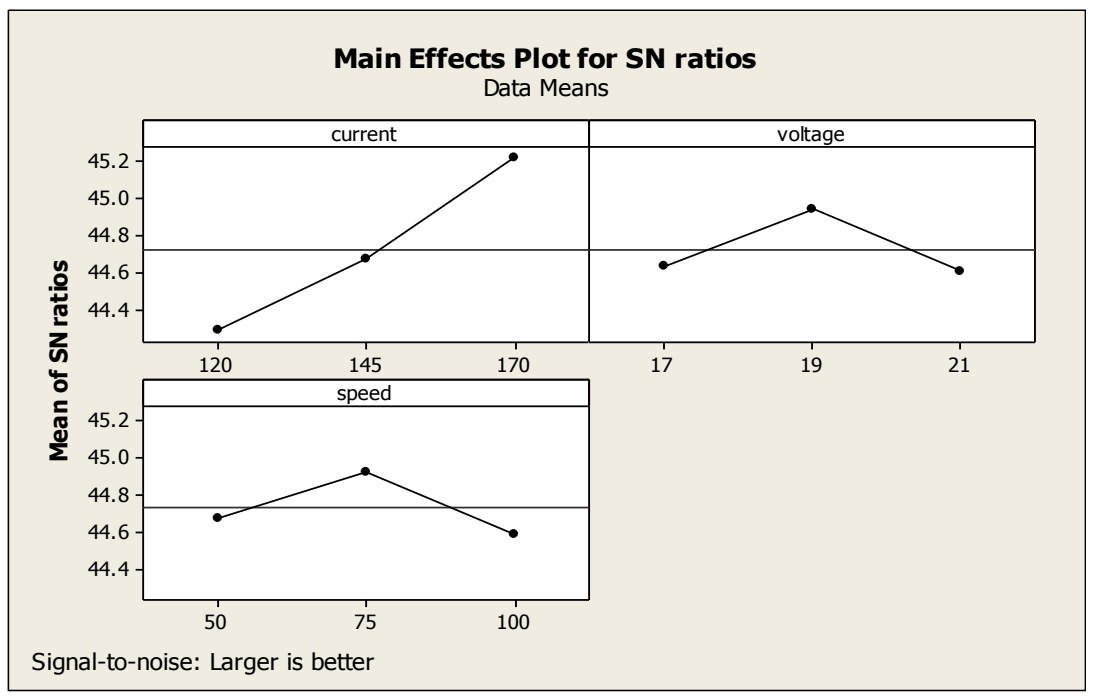

Figure 10. Graph of SN ratio against parameter (main effects plot for SN ratio for microhardness testing). 
Table 7. Response table for signal to noise ratio for microhardness testing.

\begin{tabular}{llll}
\hline Level & Current & Voltage & Speed \\
\hline $\mathbf{1}$ & 44.29 & 44.64 & 44.67 \\
$\mathbf{2}$ & 44.68 & 44.93 & 44.92 \\
$\mathbf{3}$ & 45.22 & 44.61 & 44.59 \\
Delta & 0.93 & 0.33 & 0.33 \\
\hline Rank & 1 & 3 & 2 \\
\hline
\end{tabular}

Using the regression and correlation analysis, mathematical model for microhardness is as follows:

$$
\text { Microhardness: } 41.8-0.00102 \mathrm{I}+0.0960 \mathrm{~V}+0.0156 \mathrm{v}
$$

\section{CONCLUSIONS}

In this study, the performance of welding parameters on tensile and microhardness testing was investigated. Welding parameters which are current, voltage and jig rotational speed give variable impact to welding responses such as tensile and microhardness. The result indicates that current gave a huge impact to both responses while voltage and jig rotational speed gave a slightly different and less effect compare to current. The optimum value was indicating by plotting main effect graph while regression equation was generated. Re-weld process until second repair have indicate that each of parameters react differently to the responses. Taguchi Method have analysed that current gave a huge impact to tensile and microhardness testing.

\section{ACKNOWLEDGEMENTS}

Authors are grateful to the Faculty of Manufacturing Engineering, Universiti Teknikal Malaysia Melaka for the facilities support. This research is funded through FRGS Grant numbered FRGS/1/2015/TK03/FKP/02/F00280.

\section{REFERENCES}

[1] Aloraier A, Al-Mazrouee A, Price JWH, Shehata T. Weld repair practices without post weld heat treatment for ferritic alloys and their consequences on residual stresses: A review. Int. Journal of Pressure Vessels and Piping, 2010;87:127-133.

[2] Eisazadeh H, Bunn J, Coules HE, Achuthan A, Goldak J, Aidun DK. A Residual stress study in similar and dissimilar welds. Welding Research Journal, 2016;95:111119.

[3] Varghese P, Prasad MS, Joseph F, Varkey MJ, Anthony K, Sreekanth A. The effect of repeated repair welding on the corrosion behavior of austenitic stainless steel and mild steel dissimilar weldment. Proceeding of International Conference on Advanced in Materials, Manufacturing and Applications. 2015;864 7869 . 
[4] Debnath S, Mukherjee M, Pal TK. Study on microstructure and mechanical properties of thick low-alloy quench and tempered steel welded joint. Material Performance and Characterization, 2004;3(1):23-48.

[5] Hsieh CC, Lin DY, Chen MC, Wu W. Microstructure, recrystallization, and mechanical property evolutions in the heat-affected and fusion zones of dissimilar stainless steels. Materials Transactions. 2007;48(11):2898-2902.

[6] Wan Muda, WSH. et al. Effect of welding heat input on microstructure and mechanical properties at coarse grain heat affected zone of ABS grade a steel. ARPN Journal of Engineering and Applied Sciences, 2015:10(20):9487-9495.

[7] Varma Prasad, VM. et al. 3D Simulation of residual stress developed during TIG welding of stainless steel pipes. Procedia Technology, 24:364-371.

[8] Vega OE et al. Effect of multiple repairs in girth welds of pipelines on the mechanical properties. Materials Characterization, 2016;59(10):1498-1507.

[9] Venkata KA et al. Characterising electron beam welded dissimilar metal joints to study residual stress relaxation from specimen extraction. International Journal of Pressure Vessels and Piping, 2016;139-140:237-249.

[10] Shoeb M. Effect of MIG welding input process parameters on weld bead geometry on HSLA Steel. International Journal of Engineering \& Technology, 2013;5(1):200212.

[11] Singh J, Bhinder SS. Effect of welding speed on depth of penetration during arc welding of mild steel plates, 2014;5762:50-52.

[12] Sivaraos et al. Comparison between taguchi method and response surface methodology (RSM) in modelling CO2 laser machining. Jordan Journal of Mechanical and Industrial Engineering, 2014;8(1):35-42.

[13] Oluwole OI, Ajibade OJ. Effect of welding current and voltage on the mechanical properties of wrought (6063) aluminium alloy 2. Experimental Procedure 3. Mechanical Tests. 2010;13(2):125-128.

[14] Mohammed G et al. Effects of heat input on microstructure, corrosion and mechanical characteristics of welded austenitic and duplex stainless steels: A review. Metals, 2017;7(2):39.

[15] Hussein NI, Ayof MN, Kean TH. Review on effect of repetitive rework on dissimilar austenistic stainless steel pipe by using GMAW orbital welding, 2015; 789-790:146150.

[16] Ayof MN, Noh MZ, Hussein NI. Mechanical properties comparison of stainless steel 304L and carbon steel BS 1387 prior to orbital welding, 2015; 761: 79-82.

[17] Hussein NI, Ayof MN, Rasidi MKS. Microhardness of nickel tungsten carbide overlay on gray cast iron using gas metal arc welding for hardfacing process, 2017, 45.

[18] Mathews PG. Design of Experiments with MINITAB. 2004.

[19] Nora O, Zainuddin S, Mohd ZO. Multi-pass friction stirred clad welding of dissimilar joined AA6061 aluminium alloy and brass, Journal of Mechanical Engineering and Sciences, 2018; 12(4):4285-4299. 